\title{
Self Efficacy dan Gaya Hidup Pasien Hipertensi
}

\author{
Amila1, Janno Sinaga ${ }^{2}$, Evarina Sembiring ${ }^{3}$ \\ ${ }^{1,2}$ Program Studi Ners, Universitas Sari Mutiara Medan, Indonesia \\ ${ }^{3}$ Program Studi Kesehatan Masyarakat, Universitas Sari Mutiara Medan, Indonesia \\ Email: mila_difa@yahoo.co.id
}

\begin{abstract}
Self-efficacy and Life Style on Hypertension Patients. Hypertension is one of the major cardiovascular diseases worldwide. Self-efficacy, a widely used psychosocial concept, is associated with the ability to manage chronic disease. The purposes of this study were to identify the correlation between self-efficacy with lifestyle on hypertension patients. The data obtained were analyzed by correlational analytic with a cross-sectional approach. The sample of this study was recruited with total sampling as much as 130 people. Data were collected with a questionnaire toward the hypertension patients who came to Mutiara Homecare Medan. The data were analyzed by Spearman correlation with significance $\alpha<0.05$. The study showed that selfefficacy of patients with hypertension was majorly high(96,9\%), and lifestyle was a majorly healthy lifestyle $(96,2 \%)$. There was a significant correlation between self-efficacy with lifestyle on hypertension patients $(\mathrm{r}=0.8 .91 ; \mathrm{p}<0.05)$. Nurses can increase self-efficacy of hypertension patients by providing support and motivation to improve a healthy lifestyle to prevent further complications.
\end{abstract}

Keywords: Lifestyle, Hypertension, Self-efficacy

\begin{abstract}
Abstrak: Self Efficacy dan Gaya Hidup Pasien Hipertensi. Hipertensi merupakan salah satu penyakit kardiovaskular di dunia. Self efficacy umumnya dihubungkan dengan kemampuan seseorang (self management) untuk mengatur penyakit kronik. Penelitian ini bertujuan untuk mengidentifikasi hubungan self efficay dengan gaya hidup pada pasien hipertensi di Mutiara Homecare Medan. Jenis penelitian ini adalah analitik korelasi dengan pendekatan cross sectional. Populasi penelitian ini adalah seluruh pasien hipertensi yang melakukan kunjungan ke Mutiara Homecare Medan. Sampel diambil secara total sampling dan didapatkan 130 orang. Data yang terkumpul diuji secara statistik dengan uji Spearman. Hasil penelitian menunjukkan mayoritas responden memiliki self efficacy tinggi sebanyak 96,1\%, melakukan gaya hidup sehat sebanyak $96,2 \%$. Hasil uji statistik menunjukkan adanya hubungan yang sangat kuat antara self efficacy dengan gaya hidup pada pasien hipertensi $(r=0,891, p<0.05)$. Perawat dapat meningkatkan self efficacy pasien hipertensi dengan memberikan dukungan dan motivasi agar meningkatkan gaya hidup sehat untuk mencegah komplikasi lanjut.
\end{abstract}

Kata kunci: Gaya hidup, Hipertensi, Self efficacy

Penyakit hipertensi atau tekanan darah tinggi merupakan peningkatan tekanan darah persisten yang juga dijuluki pembunuh diamdiam atau silent killer karena tidak memiliki gejala yang khas sehingga seseorang yang mengidap hipertensi selama bertahun-tahun tidak menyadari sampai terjadi kerusakan organ vital yang cukup berat yang bahkan dapat menyebabkan kematian (Hafiz, Weta, \& Ratnawati, 2016).

Menurut World Health Organization (WHO) tahun 2015, diperkirakan tahun 2020 sekitar 1,56 miliar orang dewasa akan hidup dengan hipertensi. Penduduk Amerika usia diatas 20 tahun yang menderita hipertensi telah mencapai angka hingga 74,5 juta jiwa (Kemenkes
RI, 2014). Hipertensi di Indonesia menjadi masalah kesehatan dengan prevalensi yang tinggi yaitu sebesar 25,8\%. Prevalensi tertinggi di Bangka Belitung (30,9\%), diikuti Kalimantan Selatan (30,8\%), Kalimantan Timur $(29,6 \%)$, Jawa Barat $(29,4 \%)$, Gorontalo $(29,4 \%)$ dan Sumatera Utara (25\%). Prevalensi hipertensi meningkat dikarenakan tidak mendapat penanganan yang baik sehingga menyebabkan komplikasi seperti stroke, penyakit jantung koroner, diabetes, gagal ginjal dan kebutaan (Kemenkes RI, 2014).

Prevalensi hipertensi akan semakin meningkat apabila penanganan hipertensi tidak dilakukan sejak dini. Hal ini sejalan dengan Novian (2013) yang mengemukakan bahwa bagi 
individu yang mempunyai faktor risiko hipertensi harus waspada serta melakukan upaya pencegahan sedini mungkin. Penanganan hipertensi terdiri dari penatalaksanaan farmakologi atau dengan obat yang saat ini memang telah mengalami kemajuan, tetapi terdapat banyak laporan yang menyampaikan bahwa penderita hipertensi yang datang ke Rumah Sakit akan datang lagi dengan keluhan tekanan darahnya tidak mengalami penurunan bermakna meskipun sudah minum obat sehingga harus diikuti dengan penatalaksanaan nonfarmakologi dengan memodifikasi gaya hidup (Suoth, Bidjuni, \& Malara, 2014).

Gaya hidup sehat menjadi bagian yang penting dalam penanganan hipertensi dengan mengurangi berat badan untuk individu yang gemuk, mengadopsi pola makan DASH (Dietary Approach to Stop Hypertension), melakukan aktifitas fisik/olahraga, menghindari alkohol, kafein dan kebiasaan merokok agar tidak menimbulkan hipertensi berat yang mungkin disertai dengan komplikasi yang berbahaya (Triyanto, 2014). Hasil penelitian (Suoth et al., 2014) menunjukkan ada Hubungan Gaya Hidup dengan Kejadian Hipertensi di Puskesmas Kolongan Kecamatan Kalawat Kabupaten Minahasa Utara dengan nilai $p$-value $(\alpha) 0,05$.

Beberapa hasil penelitian menyebutkan bahwa ada hubungan antara self efficacy dan penyakit kronik seperti hipertensi, diabetes dan arthritis, salah satunya Okatiranti, Irawan, \& Amelia (2017) menunjukkan ada hubungan antara self efficacy dengan perawatan diri lansia hipertensi di Salah Satu Puskesmas di Kota Bandung $(p<0.05)$.

Dalam memodifikasi gaya hidup, pasien hipertensi harus memiliki self efficacy yang tinggi untuk memotivasi dan meyakinkan diri sendiri mampu mencapai gaya hidup yang sehat. Hasil penelitian Warren-Findlow (2012) self efficacy yang baik secara signifikan dihubungkan dengan kepatuhan pengobatan, diet rendah garam. Dengan memiliki self efficacy yang tinggi pasien hipertensi mampu menjalankan gaya hidup sehat sehingga meminimalkan komplikasi serta meningkatkan kualitas hidupnya dan pasien yang memiliki self efficacy yang rendah lebih cenderung tidak memperhatikan gaya hidup sehat (Indah, Mamat, \& Supriadi, 2014).

Berdasarkan survei pendahuluan yang dilakukan peneliti kepada 5 pasien hipertensi di unit rawat jalan, 2 pasien mengatakan yakin bahwa hipertensi yang dideritanya akan sembuh jika rutin memeriksa tekanan darah dan minum obat, 1 pasien mengatakan yakin bahwa tekanan darahnya dapat dikendalikan tetapi kurang bisa menghindari makanan yang dapat meningkatkan tekanan darah seperti suka makan daging karena pasien langsung minum obat ketika merasakan pusing dan 2 pasien lain mengatakan tidak dapat mengendalikan keinginannya untuk merokok dan minum kopi tetapi runtin untuk melakukan cek tekanan darah.

Tujuan penelitian adalah mengetahui hubungan self efficacy dengan gaya hidup pada pasien hipertensi di Mutiara HomecareKota Medan. Penelitian ini diharapkan memberikan informasi mengenai perilaku gaya hidup pasien hipertensi, memodifikasi gaya hidup dan memotivasi pasien hipertensi agar meningkatkan self efficacy pasien hipertensi.

\section{METODE}

Penelitian ini merupakan deskriptif korelasi dengan pendekatan cross sectional, berjumlah 130 orang yang ditetapkan dengan total sampling. Penelitian ini dilaksanakan di Mutiara Homecare pada bulan April-Juli 2018.

Instrumen yang digunakan untuk menilai Self Efficacy menggunakan kuesioner yang sudah pernah digunakan oleh peneliti sebelumnya yaitu Huda (2017) dengan nilai reliabilitas 0.746 dan validitas, untuk menilai gaya hidup menggunakan kuesioner yang sudah pernah digunakan oleh peneliti sebelumnya yaitu Panjaitan (2015) dengan nilai reliabilitas 0,988 .

Uji korelasi antara masing-masing variabel bebas dan variabel terikat dilakukan dengan uji korelasi Spearman.

\section{HASIL}

\section{Tabel 1. Distribusi Frekuensi Karakteristik} Responden

\begin{tabular}{lcc}
\hline \multicolumn{1}{c}{ Karakteristik responden } & f & \% \\
\hline Umur & & \\
42-55 tahun & 46 & 35,4 \\
56-69 tahun & 84 & 64,6 \\
\hline Jenis kelamin & & \\
Laki-laki & 59 & 45,4 \\
Perempuan & 71 & 54,6 \\
\hline Pendidikan & & \\
SD & 6 & 4,6 \\
SMP & 16 & 12,3 \\
SMA & 63 & 48,5 \\
D3 & 25 & 19,2 \\
S1 & 20 & 15,4 \\
\hline Lama Sakit & & \\
6-16 tahun & 71 & 54,6 \\
17-27 tahun & 59 & 45,4 \\
\hline
\end{tabular}


Berdasarkan tabel 1 dapat dilihat bahwa karakteristik responden mayoritas berusia antara 56-69 tahun $64,6 \%$, berjenis kelamin perempuan $54,6 \%$, pendidikan SMA $48,5 \%$, dan lama sakit, 6-16 tahun $54,6 \%$.

Tabel 2. Distribusi Frekuensi Self Efficacy pada Pasien Hipertensi

\begin{tabular}{lrr}
\hline \multicolumn{1}{c}{ Self Efficacy } & \multicolumn{1}{c}{ f } & \multicolumn{1}{c}{$\%$} \\
\hline Rendah & 4 & 3,1 \\
Tinggi & 126 & 96,9 \\
\hline
\end{tabular}

Berdasarkan tabel 2 menunjukkan bahwa mayoritas responden yang menilai self efficacy tergolong tinggi sebanyak $96,1 \%$.

Tabel 3. Distribusi Frekuensi Berdasarkan Gaya Hidup pada Pasien Hipertensi

\begin{tabular}{lrr}
\hline Gaya Hidup & \multicolumn{1}{c}{ f } & \multicolumn{1}{c}{$\%$} \\
\hline Tidak Sehat & 5 & 3,8 \\
Sehat & 125 & 96,2 \\
\hline
\end{tabular}

Berdasarkan tabel 3 menunjukkan bahwa mayoritas responden telah melakukan gaya hidup sehat sebanyak $96,2 \%$.

Tabel 4. Hubungan Self Efficacy dengan Gaya Hidup Pada Pasien Hipertensi

\begin{tabular}{|c|c|c|c|c|c|c|}
\hline \multicolumn{7}{|c|}{ Gaya Hidup } \\
\hline \multirow[t]{2}{*}{$\begin{array}{c}\text { Self } \\
\text { Efficacy }\end{array}$} & \multicolumn{2}{|c|}{$\begin{array}{l}\text { Tidak } \\
\text { sehat }\end{array}$} & \multicolumn{2}{|c|}{ Sehat } & \multicolumn{2}{|c|}{ Total } \\
\hline & f & $\%$ & f & $\%$ & f & $\%$ \\
\hline Rendah & 4 & 3,1 & 0 & 0 & 4 & 3,1 \\
\hline Tinggi & 1 & 0,8 & 125 & 96,2 & 126 & 96,9 \\
\hline Jumlah & 5 & 3,9 & 125 & 96,2 & 130 & 100 \\
\hline$p$-value & 0,0 & & & & & \\
\hline $\mathrm{R}$ & 0,8 & & & & & \\
\hline
\end{tabular}

Berdasarkan tabel 4 dapat dilihat bahwa responden dengan self efficacy rendah dan gaya hidupnya tidak sehat $3,1 \%$. Sedangkan responden self efficacy tinggi $96,9 \%$ dengan gaya hidup tidak sehat $0,8 \%$ dan gaya hidup sehat $96,2 \%$. Hasil uji statistik menunjukkan ada hubungan antara self efficacy dengan gaya hidup pasien hipertensi $\quad(p$-value $=0,001)$ dengan kekuatan hubungan termasuk kuat dengan nilai $\mathrm{r}=+0,891$ yang artinya kekuatan hubungan sangat kuat dan semakin tinggi self efficacy responden maka semakin baik pula gaya hidup responden.

\section{PEMBAHASAN}

\section{Self Efficacy Pasien Hipertensi}

Berdasarkan hasil penelitian yang dilakukan di Mutiara Homecare Kota Medan menunjukkan bahwa mayoritas responden memiliki self efficacy tinggi sebanyak 96,9\%. Hal ini diperoleh dari hasil jawaban responden sebanyak 130 orang dan kuesioner tentang self efficacy dengan 10 pernyataan sehingga menunjukkan bahwa pasien hipertensi memiliki self efficacy yang tinggi dalam mengubah gaya hidup.

Self efficacy memberikan kontribusi terhadap pemahaman yang lebih baik dalam proses perubahan perilaku kesehatan sehingga sangat penting untuk meningkatkan pengetahuan, perilaku dan keterampilan seseorang. Seseorang dengan self efficacy yang tinggi akan menganggap bahwa dirinya mampu menggunakan kemampuan untuk mencapai suatu hasil yang baik sesuai dengan apa yang diharapkan. Begitu pula sebaliknya, apabila seseorang dengan self efficacy yang rendah akan menganggap bahwa kemampuan yang dimiliki belum tentu dapat membuat dia mampu untuk mendapatkan hasil yang diharapkan (Arsyita, 2016).

Menurut Okatiranti, Irawan, \& Amelia (2017) tinggi rendahnya self efficacy pada diri seseorang disebabkan oleh beberapa faktor yaitu usia, jenis kelamin, tingkat pendidikan, dan pengalaman. Hal ini juga sama hal dengan pasien hipertensi di Mutiara Homecare. Berdasarkan hasil penelitian ini didapat mayoritas usia antara 56-69 tahun sebanyak $64,6 \%$, self efficacy usia lansia terkait pada penerimaan dan penolakan terhadap kemampuan yang dimiliki seiring dengan terjadinya kemunduran fisik yang dialami. Selain itu, pengalaman pasien terhadap gaya hidupnya juga berhubungan dengan lama sakit. Ketika pengalaman yang dialami adalah baik artinya pasien dapat membuat kesehatannya lebih baik sehingga dari pengalaman tersebut dapat meningkatkan motivasi untuk melakukan gaya hidup sehat. Namun jika pengalaman sebelumnya tidak baik maka dari pengalaman tersebut akan menurunkan motivasinya dalam melakukan perawatan diri sehingga dapat terjadi penurunan kesehatannya.Pada penelitian ini, mayoritas lama sakit pasien 6-16 tahun sebanyak $54,6 \%$.

Pada penelitian Wantiyah, (2010) mengatakan bahwa faktor yang lebih berpengaruh dalam self efficacy pasien adalah pengetahuan pasien. Pengetahuan yang tinggi akan meningkatkan self efficacy pasien. Pendidikan erat dihubungkan dengan pengetahuan dan bukan merupakan salah satu penyebab terjadinya hipertensi akan tetapi pendidikan dapat mempengaruhi gaya hidup. Berdasarkan hasil penelitian ini didapat 
mayoritas pendidikan responden SMA sebanyak $48,5 \%$. Semakin tinggi tingkat pendidikan dan pengetahuan pasien diharapkan akan berdampak pada peningkatan gaya hidup sehat.

Hasil penelitian ini menunjukkan bahwa jenis kelamin mayoritas perempuan sebanyak 54,6\%. Pada penelitian Huda (2017), perempuan lebih mungkin mengendalikan tekanan darah dibanding laki-laki. Dalam budaya Indonesia, sebagian besar laki-laki adalah pekerja dan hal ini mungkin disebabkan karena laki-laki memiliki peran penting dalam keluarga sehingga tidak banyak waktu dalam mengontrol tekanan darah mereka.

\section{Gaya Hidup Pasien Hipertensi}

Dari hasil penelitian yang dilakukan pada pasien hipertensi di Mutiara Homecare Kota Medan didapat bahwa mayoritas responden sudah memiliki gaya hidup sehat sebesar 96,2\%. Hal ini didapatkan dari hasil jawaban responden sebanyak 130 orang pada kuesioner yang diberikan dengan 20 pernyataan tentang gaya hidup pasien hipertensi yang bersifat positif dan negatif.

Gaya hidup sehat pada pasien hipertensi berguna untuk pengelolaan dan pengendalian faktor resiko komplikasi yang mungkin terjadi dan juga mengurangi tingkat keparahan pada pasien yang sudah mengalami komplikasi. Gaya hidup sehat meliputi pengendalian berat badan, tidak merokok, tidak minum-minuman beralkohol dan berkafein, berolahraga dan memonitoring/mengecek tekanan darah secara teratur. Gaya hidup yang efektif dapat meningkatkan kemandirian, kepercayaan diri serta kualitas hidup pasien hipertensi (Indah, Mamat, \& Supriadi, 2014).

Hal ini sejalan dengan penelitian yang dilakukan oleh Alvino, Sunarti, \& Sunarno (2015) di Poli Umum UPTD Kesehatan Kecamatan Sukorejo Kota Blitar yang menunjukkan bahwa upaya penderita hipertensi dalam mempertahankan gaya hidup sehat dalam kategori baik $57,6 \%$ yang berarti ada hubungan antara pola hidup sehat dengan penurunan tekanan darah. Tetapi ada juga responden yang memiliki gaya hidup yang tidak sehat, hal ini dibuktikan dari hasil analisa kuesioner, bahwa responden masih ada yang mengkonsumsi alkohol dan kebiasaan merokok sebanyak 3,1\%.

Menurut Puspita (2009), gaya hidup dipengaruhi oleh beberapa faktor yaitu faktor pembelajaran, sosial dan emosi dan faktor persepsi dan kognitif. Sama halnya dengan hasil wawancara peneliti terhadap pasien di Mutiara
HomecareKota Medan bahwa perubahan gaya hidup dipengaruhi oleh faktor persepsi dan kognitif yaitu ketika pasien mengetahui dengan pasti tentang gaya hidup sehat dan memahami cara mengatasi masalah yang timbul maka pasien tahu kapan berperilaku baik dan buruk sehingga hal ini meningkatkan gaya hidup sehat. Tetapi apabila pasien tidak mengetahui dengan pasti tentang gaya hidup sehat, mereka tidak akan tahu bagaimana mengatasi masalah yang timbul dan tidak tahu kapan berperilaku baik dan buruk. Hal ini yang menyebabkan gaya hidup yang tidak sehat. Begitupula dengan hasil penelitian ini yang menunjukkan ada responden memiliki self efficacy tinggi tetapi dengan gaya hidup yang tidak sehat sebanyak $0,8 \%$.

\section{Hubungan Self Efficacy dengan Gaya Hidup Pasien Hipertensi}

Berdasarkan hasil uji statistik didapatkan ada hubungan antara self efficacy dengan gaya hidup dengan nilai $p$-value $=0,001$ dan nilai $\mathrm{r}=0,891$ yang artinya koefisien korelasi yang kuat. Hal ini dapat dikatakan bahwa semakin tinggi self efficacy pasien maka akan semakin baik atau sehat juga gaya hidup pasien hipertensi. Hal ini sesuai dengan pendapat yang disampaikan oleh Ghufron \& Risnawati (2016) bahwa seseorang dengan self efficacy yang tinggi percaya bahwa mereka mampu melakukan gaya hidup sehat dan berusaha lebih keras untuk mengatasi setiap tantangan yang ada sedangkan self efficacy yang rendah cenderung akan mudah menyerah dan menganggap bahwa pada dasarnya dirinya tidak mampu melakukan gaya hidup sehat.

Didukung dengan penelitian yang dilakukan oleh Harsono (2017) dengan judul Hubungan Self efficacy Dengan Manajemen Perawatan Diri Pada Penderita Hipertensi Di Desa Pringapus Kecamatan Pringapus Kabupaten Semarang yang menunjukkan bahwa ada hubungan antara self efficacy dengan manajemen perawatan diri pada pasien hipertensi. Semakin tinggi self efficacy yang dimiliki seseorang maka akan semakin baik pula perawatan diri yang dilakukan oleh pasien hipertensi.

Dari hasil penelitian ini juga didapatkan bahwa responden yang menilai self efficacy tergolong tinggi $96,9 \%$, terdapat $3,8 \%$ diantaranya memiliki memiliki gaya hidup yang tidak sehat dan 3,1\% self efficacy yang tergolong rendah, 96,2\% diantaranya melakukan gaya hidup yang sehat. Hasil penelitian ini menunjukkan tidak selamanya self efficacy mempengaruhi gaya hidup pasien hipertensi. Hal 
ini dapat dipengaruhi oleh beberapa faktor diantaranya faktor pengalaman keberhasilan, pengalaman orang lain, persuasi verbal dan kondisi fisiologis.

Pasien yang kurang sadar akan pentingnya gaya hidup menyebabkan kekambuhan penyakit hipertensi yang berulang dan bahkan dapat menyebabkan komplikasi hingga pada kematian. Gaya hidup dianggap sulit dilakukan karena kurang pemahaman dan dukungan dari orang terdekat atau lingkungan (Hanafi, 2016). Hal ini sejalan dengan penelitian yang dilakukan oleh (Alvino et al., 2015) yang mengatakan bahwa gaya hidup berperan penting terhadap kesehatan.

Melakukan gaya hidup sehat untuk pencegahan hipertensi dan peningkatan kesehatan dalam diri individu diperlukan self efficacy dengan meningkatkan keyakinan individu menjalankan gaya hidup sehat, perawatan diri dan pengelolaan hipertensi. Didukung hasil penelitian Permatasari et al. (2014) menyatakan bahwa dalam melakukan perawatan diri, self efficacy merupakan faktor yang paling dominan dalam pengelolaan hipertensi.

Keterbatasan dalam penelitian ini, responden yang dijadikan sampel adalah seluruh pasien hipertensi tidak terkecuali pasien hipertensi yang terkomplikasi sehingga gaya hidup pasien ada beberapa yang bias. Dan beberapa variabel yang kemungkinan dapat menimbulkan bias karena tidak bisa dikontrol

\section{DAFTAR PUSTAKA}

Alvino, Sunarti, \& Sunarno, I. 2015. Upaya Penderita Hipertensi untuk Mempertahankan Pola Hidup Sehat. Jurnal Keperawatan Terapan, 1(2), 41-47.

Arsyita, S. 2016. Hubungan Dukungan Keluarga dengan Self Efficacy Pada Pasien Dengan Penyakit Stroke di Ruang Rawat Jalan Poli Saraf Rumah Sakit Umum Daerah Sultan Syarif Mohamad Alkadrie Kota Pontianak. ProNers, 3(1).

Ghufron, \& Risnawati. 2016. Teori-teori Psikologi. (R. Kusumaningratri, Ed.). Yogyakarta: Ar-Ruzz Media.

Hafiz, M., Weta, I. W., \& Ratnawati, N. L. K. A. 2016. Faktor-Faktor Yang Berhubungan Dengan Kejadian Hipertensi Pada Kelompok Lanjut Usia di Wilayah Kerja UPT Puskesmas Petang I Kabupaten Badung Tahun 2016. E-Jurnal Medika, 5(7), 1-23.

Hanafi, A. 2016. Gambaran Gaya Hidup Penderita Hipertensi di Kecamatan sepenuhnya seperti pengalaman dan motivasi dari responden dalam melakukan gaya hidup.

\section{SIMPULAN}

Penelitian ini menunjukkan hubungan yang sangat kuat antara self efficacy dengan gaya hidup pasien hipertensi di Mutiara Homecare.

Perawat dapat meningkatkan self efficacy pasien dengan membangun kepercayaan diri, memotivasi pasien terhadap kemampuannya melaksanakan perilaku yang sehat untuk mengontrol hipertensi.

\section{SARAN}

Disarankan kepada petugas kesehatan Mutiara Home Care meningkatkan upaya promotif dan preventif untuk meningkatkan keyakinan dan pengetahuan masyarakat dalam mengontrol hipertensi, seperti pemeriksaan rutin tekanan darah, diet rendah garam dan lemak, rutin melakukan aktivitas fisik, tidak merokok, mengendalikan stres, monitoring berat badan.

Perlu melakukan penelitian lebih lanjut tentang hubungan self efficacy dengan perawatan diri pasien hipertensi, analisis faktor yang mempengaruhi self management behaviour pasien hipertensi.
Sumowono Kabupaten Semarang. [Skripsi]. Semarang: Fakultas Kedokteran, Universitas Diponegoro..

Harsono, J. 2017. Hubungan Efikasi Diri Dengan Manajemen Perawatan Diri Pada Penderita Hipertensi Di Desa Pringapus Kecamatan Pringapus Kabupaten Semarang. [Skripsi]. Fakultas Keperawatan, Universitas Ngudi Waluyo Ungaran.

Huda, S. 2017. Huungan Antara Efikasi Diri Dengan Manajemen Perawatan Diri Pada Penderita Hipertensi Dewasa Di Kabupaten Jepara. Keperawatan Dan Kesehatan Masyarakat, 2(5).

Indah, P. L.,Mamat, L., \& Supriadi. 2014. Hubungan dukungan keluarga dan self efficacy dengan perawatan diri lansia hipertensi. Jurnal Kesehatan Komunitas Indonesia, 10, 993-1003.

Kementerian Kesehatan Republik Indonesia. 2014. Pusdatin Hipertensi. Infodatin, (Hipertensi), 1-7. 
https://doi.org/10.1177/109019817400200 403

Novian, A. 2014. Faktor yang Berhubungan dengan Kepatuhan Diit Pasien Hipertensi (Studi Pada Pasien Rawat Jalan di Rumah Sakit Islam Sultan Agung Semarang Tahun 2013). Unnes Journal of Public Health, 3(3).

Okatiranti, Irawan, E., \& Amelia, F. 2017. Hubungan Self Efficacy Dengan Perawatan Diri Lansia Hipertensi. Jurnal Keperawatan BSI, V(2), 130-139. http://ejournal.bsi.ac.id/ejurnal/index.php/j $\mathrm{k} /$ article/view/2631

Panjaitan, R. 2015. Hubungan Gaya Hidup dengan Kejadian Hipertensi di Wilayah Kerja Puskesmas Helvetia Medan tahun 2015. [Skripsi]. Medan: Fakultas Keperawatan dan Kebidanan, Universitas Sari Mutiara.

Permatasari, L., Lukman, M., Supriadi. 2014. Hubungan Dukungan Keluarga dan Efikasi Diri dengan Perawatan Diri Lansia Hipertensi. Jurnal Kesehatan Komunitas Indonesia.

Puspita, R. W. 2009. Gaya Hidup Pada Mahasiswa Penderita Hipertensi. [Skripsi].
Surakarta: Fakultas Psikologi, Universitas Muhammadiyah Surakarta.

Suoth, M., Bidjuni, H., \& Malara, R. T. 2014. Hubungan Gaya Hidup dengan Kejadian Hipertensi di Puskesmas Kolongan Kecamatan Kalawat Kabupaten Minahasa Utara. Ejournal Keperawaan (E-Kp), 2(1), $1-10$.

Triyanto, E. 2014. Pelayanan Keperawatan Bagi Penderita Hipertensi Secara Terpadu. Yogyakarta: Graha Ilmu.

Warren-Findlow, J., Seymour, R. B., \& Huber, L. R. B. 2012. The association between selfefficacy and hypertension self-care activities among African American adults. Journal of community health, 37(1), $15-24$.

Wantiyah. 2010. Analisis Faktor-Faktor yang Mempengarhi Efikasi Diri Pasien Penyakit Jantung Koroner dalam Konteks Asuhan Keperawatan Di RSUD dr. Soebanji Jember. [Tesis]. Depok: Fakultas Ilmu Keperawatan, Universitas Indonesia. 